\title{
Association of Toxoplasma Gondii Infection With Diabetes Mellitus Using Nested-PCR and Sequencing
}

\author{
Sadegh Shamsinia $^{{ }^{*}}$, Abdolhossein Dalimi ${ }^{1}$ (D, Majid Pirestani ${ }^{1}$ (D), Hamidreza Majidiani ${ }^{1}$
}

1. Department of Parasitology, Faculty of Medical Sciences, Tarbiat Modares University, Tehran, Iran.

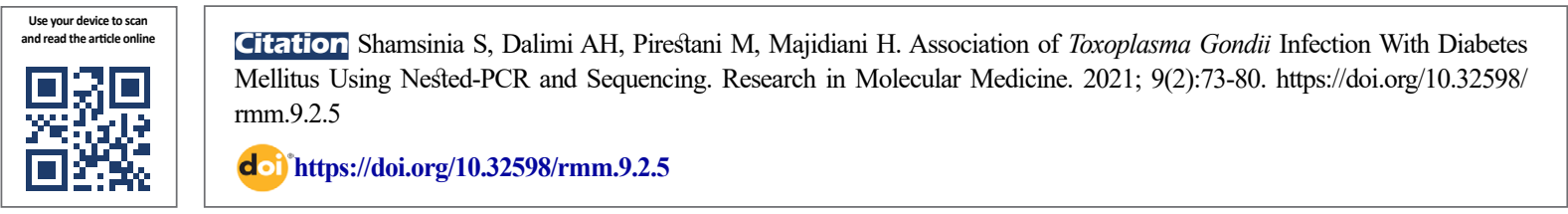

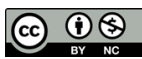

Article Type:

Brief Report

Article info:

Received: 2 March 2021

Revised: 25 Mar 2021

Accepted: 15 Apr 2021

Keywords:

Toxoplasma gondii, Genotyping, Diabetic patients, Iran

\begin{abstract}
A B S T RA C T
Background: Toxoplasmosis is a global public health concern with severe complications, particularly in pregnant women and immunosuppressed patients. Herein, we revealed the first genotypic evidence of Toxoplasma gondii (T. gondii) in diabetic and non-diabetic individuals referred to Imam Sajjad Hospital, Tehran, Iran, using nested-Polymerase Chain Reaction (PCR) and sequencing.

Materials and Methods: We collected 98, 95, and 94 blood samples from Type-1 Diabetes Mellitus (T1DM), Type-2 Diabetes Mellitus (T2DM), and control subjects from February to August 2018, and their DNA was extracted. After amplification and visualization of dense granule antigen 6 gene (344 bp) using external and internal primer pairs, the positive samples were sent for sequencing.

Results: Among 287 individuals, three T1DM patients (two IgG, one IgM) and one T2DM patient (IgG) were found positive by molecular method, which proved to be type III strain by sequencing.

Conclusion: To the best of our knowledge, this is the first genotyping investigation on $T$. gondii in diabetic individuals. Further research should be done to better realize the association between Toxoplasma genotypes and the outcome of diabetes mellitus.
\end{abstract}

\section{Introduction}

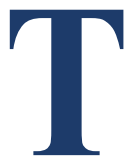

oxoplasmosis, due to Toxoplasma gondii (T. gondii), is a worldwide infection that affects a wide range of warm-blooded animals with adverse clinical outcomes, particularly in domestic livestock and humans $[1,2]$. One-third of the global human population is assumed to be seropositive regarding $T$. gondii infection, rendering it a public health concern [3-5]. Based on ethnicity and or geographical location, three major routes for transmitting Toxoplasma are meat products containing viable tissue cysts, oocyst-contaminated food/water, and congenital disease $[6,7]$. The clinical symptoms of toxoplasmosis in immunocompetent individuals are frequently mild and self-limiting comprising malaise, fever, and lymphadenopathy [8]. However, infection is more severe in pregnant women and immunocompromised individuals such as HIV/AIDS patients, representing harsh outcomes, such as retinochoroiditis, encephalitis, fetal abortion, pneumonitis, and splenomegaly [9]. The pathogenesis of $T$. gondii is predominantly affected by the number of invasive tachyzoites and the host's genetic background [10]. Parasite genotyping and strain identification by means of vari-

* Corresponding Author:

Sadegh Shamsinia, PhD.

Address: Department of Parasitology, Faculty of Medical Sciences, Tarbiat Modares University, Tehran, Iran.

Phone: +98 (912) 4839233

E-mail: sadeghshamsinia@yahoo.com 
ous molecular techniques are invaluable in epidemiological investigations for better understanding of disease outcome and its prognosis [11]. In this context, an array of molecular methods have been employed, including polymerase chain reaction-restriction fragment length polymorphism (PCRRFLP), high-resolution melting analysis, multilocus sequence typing, microsatellite analysis, Random Amplified Polymorphic (RAPD), and sequencing [12, 13]. The diversity of genotyping methods has led to the multiplicity of the isolates designation. Initial genotypic evidence based on France and USA isolates showed a clonal population composition with three main genotypes, namely type I, II, and III [14]. Further investigations demonstrated other strains, including recombinant, exotic, atypical or non-archetypal genotypes $[15,16]$.

People on high-calorie diets with inappropriate lifestyles and specific genetic backgrounds are more exposed to obesity and overweight [17]. This metabolic condition may render serious health outcomes such as Diabetes Mellitus (DM), which is caused either by dysfunction in insulin hormone release (Type 1 Diabetes [T1DM]) or decreased sensitivity of target cells to insulin (Type 2 Diabetes [T2DM]). By 2030, the morbidity rate of DM will reach 522 million cases [18]. Besides, DM pathogenesis may be associated with infectious agents such as Helicobacter pylori [19] and Coxsackie B4 virus [20]. In this sense, $T$. gondii parasitic infection has been assumed to be involved in DM casualty, as demonstrated by seroprevalence data from Iraq, Egypt, Turkey, and Czech Republic [21-27]. In this case-control study, we shed light on the possible strain(s) of Toxoplasma isolated from diabetic patients referred to Imam Sajjad Hospital, Tehran, Iran, using nested-PCR and sequencing technologies.

\section{Materials and Methods}

\section{Study design and sampling procedure}

The current study was a sequel to our recently-published case-control seroprevalence investigation on T1DM and T2DM patients with typical clinical symptoms, referred to Imam Sajjad Hospital in Tehran, Iran. We intended to understand the genotypic impact of $T$. gondii in these individuals using molecular methods. Blood samples were taken from 287 participants (235 men and 52 women), including 98, 95, and 94 subjects in T1DM, T2DM, and control groups, respectively, from February to August 2018 [28]. These individuals were matched in terms of sex and age. Besides, the control group individuals had negative tests regarding routine blood glucose assays for diabetic patients. The average age of the participants was 24.06 (T1DM), 55.84 (T2DM), and 24.43 (control) years. Of note, oral consent was taken from all participants in the study.

\section{DNA extraction and nested-PCR amplification}

DNA extraction and purification were done with an initial volume of $1 \mathrm{~mL}$ of participant's blood, based on the instructions of the FavorPrep ${ }^{\mathrm{TM}}$ Blood Genomic DNA extraction mini Kit (FAVORGEN Biotech Corp., Taiwan). The final purified product was eluted in $50 \mu \mathrm{L}$ of pre-warmed elution buffer and stored at $-20^{\circ} \mathrm{C}$ for amplification test. The nested-PCR assay on the GRA6 gene of T. gondii was performed using external (F1: 5'-ATTTGTGTTTCCGAGCAGGT-3' / R1: 5'-GCACCTTCGCTTGTGGTT-3') and internal (F2: 5'-TTTCCGAGCAGGTGACCT-3' / R2: 5'-TCGCCGAAGAGTTGACATAG-3') primer pairs in Bio-Rad thermal cycler device (Bio-Rad Laboratories, Hercules, USA).

The first-round PCR was prepared in a total volume of $15 \mu \mathrm{L}$, comprising $7.5 \mu \mathrm{L}$ MasterMix 2 (Ampliqon, Denmark), $0.5 \mu \mathrm{L}$ of each primer pair (specific to the first round), $1 \mu \mathrm{L}$ of extracted DNA, and $5.5 \mu \mathrm{L}$ of sterile distilled water. Next, $1 \mu \mathrm{L}$ of the first-round PCR product (1:100 diluted in sterile distilled water) was added to the previous reaction mixture as a DNA template and amplified by primer pairs specific to the second round. Details of the first and second rounds of nested-PCR are illustrated in Table 1. Finally, PCR products of the second round were run on $1 \%$ agarose gel electrophoresis, and possible DNA bands (344 bp) were visualized using gel-doc apparatus.

\section{Sequencing and phylogenetic analysis}

Positive DNA bands were excised from the gel and purified using GeneAll Expin ${ }^{\mathrm{TM}}$ Combo GP kit (GeneAll, South Korea), according to the manufacturer's protocol. The final purified bands were eluted in $50 \mu \mathrm{L}$ of pre-warmed sterile distilled water and sent for sequencing purposes. The obtained sequences were analyzed by Sequencher (version 4.1.4). Multiple alignments were done to evaluate the genetic diversity between isolates in the current study and those registered in the GenBank. Ultimately, the respective phylogenetic tree was drawn using the neighborjoining method in MEGA 7.0 bioinformatics software.

\section{Results}

According to our nested-PCR assay on blood samples from diabetic patients and non-diabetic control groups, only 3 out of 98 T1DM patients were positive regarding 
Table 1. Characteristics of various steps of nested-PCR assay in thermal cycler device

\begin{tabular}{|c|c|c|c|}
\hline \multicolumn{2}{|c|}{ First-round PCR } & \multicolumn{2}{|c|}{ Second-round PCR } \\
\hline \multicolumn{2}{|c|}{$94^{\circ} \mathrm{C}-5 \mathrm{~min}$} & \multicolumn{2}{|c|}{$94^{\circ} \mathrm{C}-5 \mathrm{~min}$} \\
\hline \multirow{3}{*}{35 cycles } & $94^{\circ} \mathrm{C}-30 \mathrm{~s}$ & & $94^{\circ} \mathrm{C}-30 \mathrm{~s}$ \\
\hline & $62^{\circ} \mathrm{C}-30 \mathrm{~s}$ & 35 cycles & $57.5^{\circ} \mathrm{C}-30 \mathrm{~s}$ \\
\hline & $72^{\circ} \mathrm{C}-30 \mathrm{~s}$ & & $72^{\circ} \mathrm{C}-30 \mathrm{~s}$ \\
\hline \multicolumn{2}{|c|}{$72^{\circ} \mathrm{C}-10 \mathrm{~min}$} & \multicolumn{2}{|c|}{$72^{\circ} \mathrm{C}-10 \mathrm{~min}$} \\
\hline
\end{tabular}

कrmm

T. gondii GRA6 gene amplification. Among these, two cases were IgG positive (chronic), and a single case was IgM positive (acute), based on our previous seroprevalence study [28]. Additionally, 1 out of 95 T2DM individuals showed a specific 344 bp DNA band, previously proved to be seropositive for anti-T. gondii IgG (chronic) [28] (Figure 1). Sequencing results showed that all four clinical isolates from diabetic patients in our study belonged to the type III genotype of Toxoplasma, accessible under accession numbers MN604251 to MN604254 in GenBank database (https://www.ncbi.nlm.nih.gov/ genbank). Also, the phylogenetic tree of the identified isolates was drawn in Figure 2.

\section{Discussion}

Toxoplasma is a widespread organism, as it virtually infects all warm-blooded species, including humans. Among human populations, the infection is highlighted chiefly in pregnant women and immunocompromised individuals [29]. While the humoral and cell-mediated immune functions are subdued, $T$. gondii tachyzoites could propagate in different host cells and give rise to cellular dysfunction and severe clinical outcomes, based on the involved organs [30]. This organism can manipulate the host's immunity and survive the harsh molecular milieu in the body [31]. In addition, Toxoplasma has been speculated to be involved in triggering and or progression of pathophysiological processes of some autoimmune disorders, including DM [26, 32, 33]. Until now, chronic toxoplasmosis has been significantly correlated to thyroid disease, systemic sclerosis, rheumatoid arthritis, inflammatory bowel syndrome, and hypertension in T2DM patients [34, 35].

There have been several seromolecular studies between T. gondii and DM [21, 22, 25, 27, 36-38]. We previously performed a case-control serological investigation using ELISA test regarding such association, suggesting that 16/98 T1DM, 55/95 T2DM patients, and 16/94 control subjects had previous exposure to Toxoplasma. It was deduced that seroprevalence of anti- $T$. gondii $\mathrm{IgG}$ is higher in T2DM cases than in the controls $(\mathrm{P}<0.0001)$. Accordingly, two meta-analysis studies have emphasized a potent association between Toxoplasma exposure and T2DM, but not T1DM $[32,33]$. The current study aimed to address the involved genotypes of $T$. gondii in the above groups using the nested-PCR technique and sequencing. Accordingly, amplification of the GRA6 gene was detected in 3 of 98 T1DM patients and only in 1 case of T2DM patients. Also, all PCR results for control individuals were negative.

Compared with our serological findings, PCR-based assays demonstrate much reliability in correlating exposure to Toxoplasma gondii infection and DM as a severe outcome. This issue should be considered in future research studies. The number of inoculated parasites and genetic diversity play a crucial role in Toxoplasma pathogenesis [39]. However, to the best of our knowledge, there was no molecular genotyping study on toxoplasmosis among DM cases previously, and this investigation would open new doors towards the first genetic evidence of the parasite in these individuals. Mousavi et al. had already used nested-PCR assay to amplify Toxoplasma B1 and Repeat Element (RE) gene targets in DM patients in southeastern Iran, without subsequent genotyping [40]. Although B1 is the most utilized gene target in Toxoplasma infection diagnosis [11], we employed GRA6 for molecular typing. It is a single copy gene with adequate polymorphism in its coding region to distinguish various genotypes (type I, II, and III) using the PCR-RFLP method [41].

First insights into the molecular typing of Toxoplasma in DM patients showed that type III is predominant among all four clinical isolates. Lineages of type I are noxious for mice with a complete lethal dose (LD100) of 1 parasite per mouse. Notwithstanding, lineages of type II are intermediately virulent, and type III are considered 


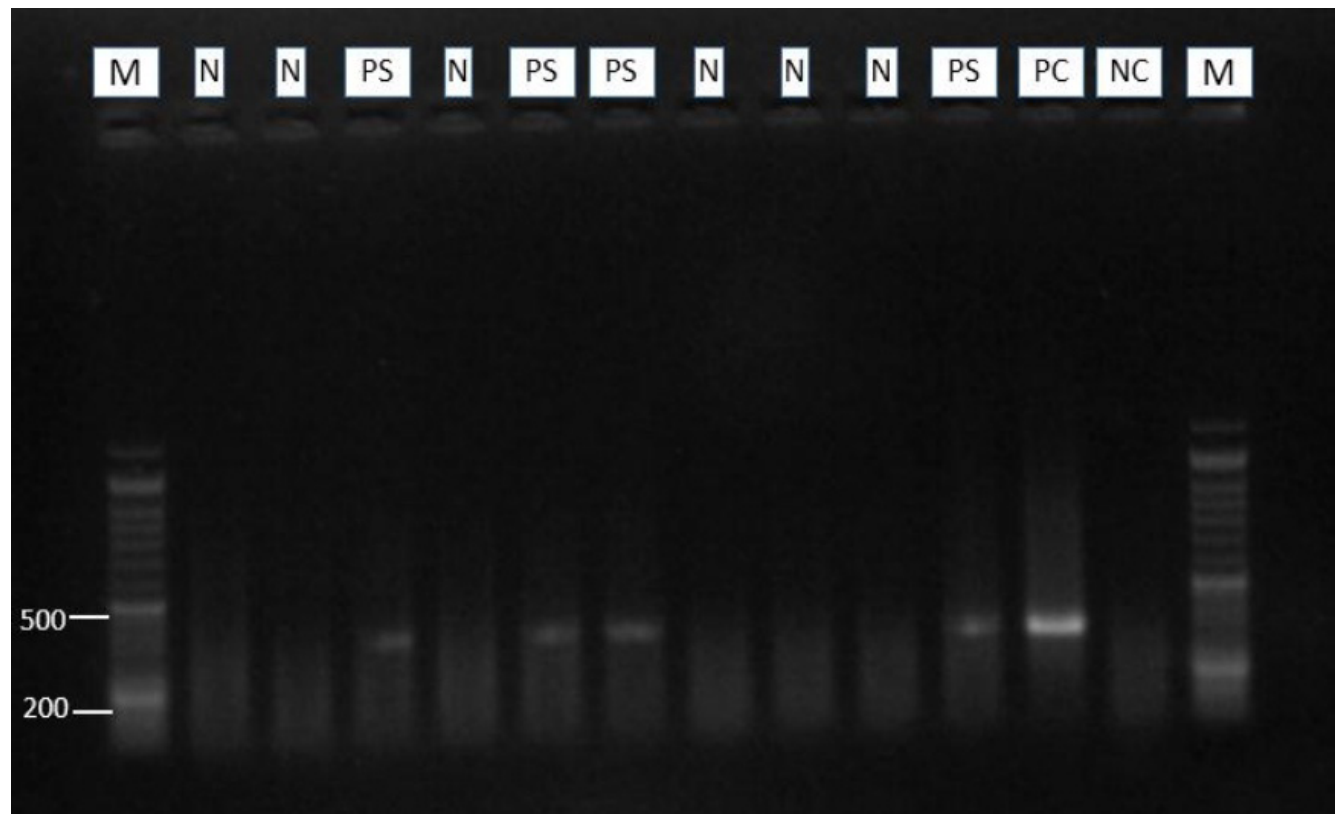

Figure 1. Visualization of amplified $344 \mathrm{bp}$ bands by nested-PCR assay

M: 50 bp DNA marker; N: Negative control; PC: Positive control; PS: Positive sample; N: Negative sample.

avirulent [29]. The distribution of genotypes varies according to geographical region and patient groups [42]. According to Hosseini et al. [12], the highest rates of type I were reported in the Americas (19.6\%), while the lowest rates were found in Africa (6.3\%). Furthermore, the highest prevalence of type II and III of T. gondii were reported from Europe (69.4\%) and America (12.4\%), respectively. Also, type III genotype was the third most

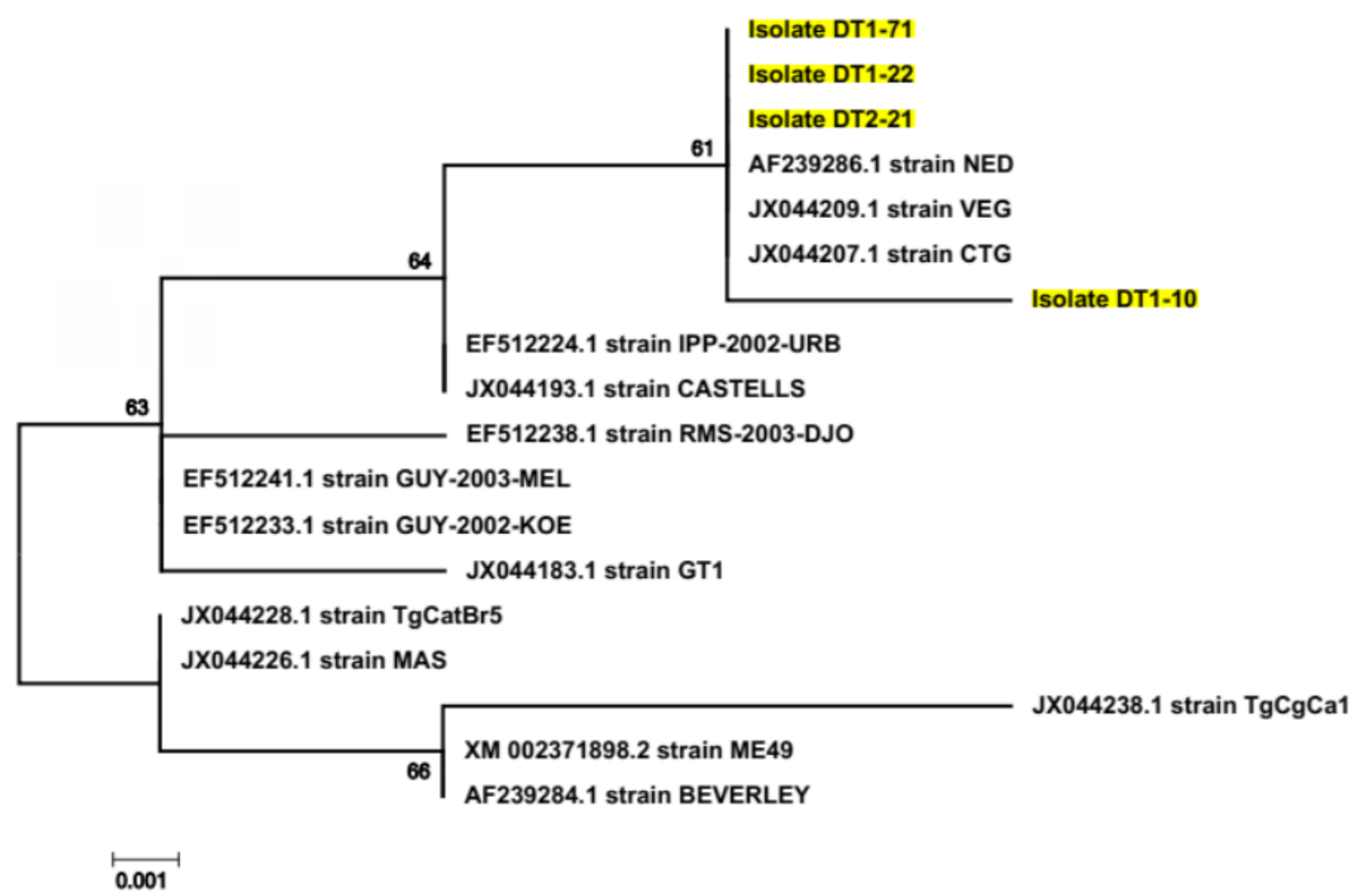

Figure 2. Phylogenetic tree of four $T$. gondii clinical isolates obtained in our investigation 
common strain (10.7\%) found in HIV/AIDS patients, as the most studied group of immunocompromised individuals, after types II (64.3\%) and I (21.4\%). The authors also reported less genetic diversity for $T$. gondii isolates in Asian and African regions than Americas [12]. Another comprehensive evaluation by Ajzenberg et al. on 88 Toxoplasma isolates in immunocompromised subjects showed that type III is the second most common genotype in such individuals, which is widely distributed in the Americas, Europe, Africa, and Asia [43].

The pathogenicity of $T$. gondii strains is multifactorial, comprising the inoculation route, host's genetic background, and life cycle stage [29]. The parasite elicits inflammatory markers such as tumor necrosis factor- $\alpha$, tissue growth actor- $\beta$ (TGF- $\beta$ ), nitric oxide synthase, and reactive oxygen species (ROS), which in turn establish chronic inflammatory condition [26]. On the other hand, the risk of insulin resistance and T2DM progression are remarkably associated with nitric oxide, ROS, and pro-inflammatory cytokines [26, 32, 44]. T. gondii infects all nucleated host cells, including fat tissue cells, which modifies inflammatory fat distribution and confers obesity as a primary risk factor of T2DM [45, 46]. Moreover, parasite manipulation in dopaminergic pathways would cause over-eating, obesity, and the subsequent T2DM [46-48]. It has been noted that TGF- $\beta$ encourages parasite intracellular replication while acting as an anti-inflammatory agent [26]. Substances with anti-Toxoplasma activity and or immunomodulatory role, such as vitamin $\mathrm{D}$, are protective, while their deficiency would contribute to DM development. There have been many other reasons for the association between $T$. gondii infection and DM remarked by Prandota; all of them implicitly declare this association [26].

\section{Conclusion}

We revealed the first molecular evidence of $T$. gondii genotypes in DM patients. Three out of four PCR positive individuals were found in T1DM patients, and three cases were associated with a chronic Toxoplasma infection (IgG positive). These findings may indicate the plausible association between toxoplasmosis and T1DM; also, higher IgG titers show that chronicity of $T$. gondii infection may have a substantial effect on diabetes initiation and or progression, which should be excavated in future research. All four clinical isolates in the current study were type III, being considered avirulent in laboratory mice. Due to the absence of molecular data on this topic, we could not compare our findings with those from other regions. Hence, we strongly recommend focused, collaborative and coordinated studies to determine Toxoplasma genotypes in diabetic patients and disease outcomes worldwide.

\section{Ethical Considerations}

\section{Compliance with ethical guidelines}

This study was approved by the Ethics Committee of Tarbiat Modares University (Code: IR.MODARES. REC.1397.179).

\section{Funding}

This work was supported by Tarbiat Modares University (Grant No.: 1398.1202)

\section{Authors contribution's}

Conceptualization: Sadegh Shamsinia and Abdolhossein Dalimi; Methodology and investigation: Sadegh Shamsinia and Majid Pirestani; Writing - original draft: Sadegh Shamsinia and Hamidreza Majidiani; Writing review and editing, supervision: Abdolhossein Dalimi.

\section{Conflict of interest}

The authors declared no conflict of interest.

\section{Acknowledgements}

The authors would like to thank all staff of the Department of Parasitology, Faculty of Medical Sciences, Tarbiat Modares University, Tehran.

\section{References}

[1] Dalimi A, Abdoli A. Latent toxoplasmosis and human. Iran J Parasitol. 2012; 7(1):1-17. [PMCID] [PMID]

[2] Daryani A, Sarvi S, Aarabi M, Mizani A, Ahmadpour E, Shokri A et al. Seroprevalence of Toxoplasma gondii in the Iranian general population: A systematic review and meta-analysis. Act Trop. 2014; 137:185-94. [DOI:10.1016/j.actatropica.2014.05.015] [PMID]

[3] Dubey J. Toxoplasmosis-a waterborne zoonosis. Vet Parasitol. 2004; 126(1-2):57-72. [DOI:10.1016/j.vetpar.2004.09.005] [PMID]

[4] Foroutan-Rad M, Khademvatan S, Majidiani H, Aryamand S, Rahim F, Malehi AS. Seroprevalence of Toxoplasma gondii in the Iranian pregnant women: A systematic review and metaanalysis. Act trop. 2016; 158:160-9. [DOI:10.1016/j.actatropica.2016.03.003] [PMID]

[5] Foroutan M, Rostami A, Majidiani H, Riahi SM, Khazaei S, Badri $\mathrm{M}$, et al. A systematic review and meta-analysis of the prevalence of toxoplasmosis in hemodialysis patients in Iran. Epidemiol Health. 2018; 40:e2018016. [DOI:10.4178/epih.e2018016] [PMID] [PMCID] 
[6] Foroutan M, Dalvand S, Daryani A, Ahmadpour E, Majidiani $\mathrm{H}$, Khademvatan S, et al. Rolling up the pieces of a puzzle: a systematic review and meta-analysis of the prevalence of toxoplasmosis in Iran. Alexandria J Med. 2018; 54(3):189-96. [DOI:10.1016/j.ajme.2017.06.003]

[7] Foroutan-Rad M, Majidiani H, Dalvand S, Daryani A, Kooti W, Saki J, et al. Toxoplasmosis in blood donors: A systematic review and meta-analysis. Transfus Med Rev. 2016; 30(3):116-22. [DOI:10.1016/j.tmrv.2016.03.002] [PMID]

[8] Tenter AM, Heckeroth AR, Weiss LM. Toxoplasma gondii: from animals to humans. Int JParasitolInt J Parasitol. 2000; 30(1213):1217-58. [DOI:10.1016/S0020-7519(00)00124-7]

[9] Saadatnia G, Golkar M. A review on human toxoplasmosis. Scand J Infect Dis. 2012; 44(11):805-14. [DOI:10.3109/0036554 8.2012.693197] [PMID]

[10] Abdoli A, Dalimi A, Soltanghoraee H, Ghaffarifar F. Molecular detection and genotypic characterization of Toxoplasma gondii in paraffin-embedded fetoplacental tissues of women with recurrent spontaneous abortion. Int J Fertil Steril. 2017; 10(4):327-36. [PMCID] [PMID] [DOI:10.22074/ijfs.2016.4569]

[11] Rostami A, Karanis P, Fallahi S. Advances in serological, imaging techniques and molecular diagnosis of Toxoplasma gondii infection. Infection. 2018; 46(3):303-15. [DOI:10.1007/s15010017-1111-3] [PMID]

[12] Hosseini S, Amouei A, Sharif M, Sarvi S, Galal L, Javidnia J, et al. Human toxoplasmosis: A systematic review for genetic diversity of Toxoplasma gondii in clinical samples. Epidemiol Infect. 2019; 147. [DOI:10.1017/S0950268818002947] [PMID] [PMCID]

[13] Shendure J, Balasubramanian S, Church GM, Gilbert W, Rogers J, Schloss JA, et al. DNA sequencing at 40: Past, present and future. Nature. 2017; 550(7676):345-53. [DOI:10.1038/nature24286] [PMID]

[14] Sibley LD, Khan A, Ajioka JW, Rosenthal BM. Genetic diversity of Toxoplasma gondii in animals and humans. Philos Trans R Soc Lond B Biol Sci Philos T R Soc B. 2009; 364(1530):2749-61. [DOI:10.1098/rstb.2009.0087] [PMID] [PMCID]

[15] Ajzenberg D, Banuls A, Su C, Dumetre A, Demar M, Carme $\mathrm{B}$, et al. Genetic diversity, clonality and sexuality in Toxoplasma gondii. Int J Parasitol. 2004;34(10):1185-96. [DOI:10.1016/j. ijpara.2004.06.007] [PMID]

[16] Grigg ME, Ganatra J, Boothroyd JC, Margolis TP. Unusual abundance of atypical strains associated with human ocular toxoplasmosis. J Infect Dis. 2001; 184(5):633-9. [DOI:10.1086/322800] [PMID]

[17] Yusefzadeh H, Rahimi B, Rashidi A. Economic burden of obesity: A systematic review. Soc Health Behav. 2019; 2(1):712. [DOI:10.4103/SHB.SHB_37_18]

[18] Canivell S, Gomis R. Diagnosis and classification of autoimmune diabetes mellitus. Autoimmun Rev. 2014; 13(4-5):403-7. [DOI:10.1016/j.autrev.2014.01.020] [PMID]

[19] Jeon CY, Haan MN, Cheng C, Clayton ER, Mayeda ER, Miller JW, et al. Helicobacter pylori infection is associated with an increased rate of diabetes. Diabetes Care. 2012; 35(3):520-5. [DOI:10.2337/dc11-1043] [PMID] [PMCID]

[20] Filippi CM, von Herrath MG. Viral trigger for type 1 diabetes: pros and cons. Diabetes. 2008; 57(11):2863-71. [DOI:10.2337/ db07-1023] [PMID] [PMCID]
[21] Beshay EVN, El-Refai SA, Helwa MA, Atia AF, Dawoud MM. Toxoplasma gondii as a possible causative pathogen of type-1 diabetes mellitus: Evidence from case-control and experimental studies. Exp Parasitol. 2018; 188:93-101. [DOI:10.1016/j.exppara.2018.04.007] [PMID]

[22] Goekce C, Yazar S, Bayram F, GÜNDOĞAN K. Toxoplasma gondii antibodies in type 1 diabetes mellitus. Turkiye Klinikleri J Med Sci. 2008; 28(5):619-22. https://avesis.erciyes.edu.tr/ yayin/7afbea94-a400-439e-b1da-e69676ea1d3c/toxoplasmagondii-antibodies-in-type-1-diabetes-mellitus

[23] Kanková S, Flegr J, Calda P. An elevated blood glucose level and increased incidence of gestational diabetes mellitus in pregnant women with latent toxoplasmosis. Folia Parasitol 2015; 62:1. [DOI:10.14411/fp.2015.056] [PMID]

[24] Khalil M, Baothman M, Alserhan F, Almunyif A, Alsharbe G, Samaren $\mathrm{H}$, et al. Prevalence of Toxoplasma gondii infection in diabetic patients in Makkah AL Mukarramah, Saudi Arabia. Trop Biomed. 2018; 35(2):464-71. https://www.researchgate. net/profile/Khalil-Ismail/publication/329044022

[25] Khattab HM, El Bassiouni SO, Abuelela MH, Elsalam DOA Seroprevalence of Toxoplasma gondii among a group of Egyptian patients with type I diabetes mellitus. Bull Nat Res Cent. 2019; 43(1):20. [DOI:10.1186/s42269-019-0059-0]

[26] Prandota J. T. gondii infection acquired during pregnancy and/or after birth may be responsible for development of both type 1 and 2 diabetes mellitus. J Diabetes Metab. 2013; 4(2):55. [DOI:10.4172/2155-6156.1000241]

[27] Saeed SA, Al-Aubaidi IK. Seroprevalence of Toxoplasmosis Antibodies among Diabetes Mellitus Patients and Assessment some Biochemical Markers. J Pur Appl Sci. 2018:539-51. [DOI:10.30526/2017.IHSCICONF.1880]

[28] Shamsinia S, Dalimi A, Pirestani M. Is Toxoplasmosis a risk factor in diabetic patients in Tehran? Infection Epidemiology and Microbiology. 2019; 5(3):49-59. https://iem.modares.ac.ir/ article-4-34776-en.pdf

[29] Behnke MS, Dubey J, Sibley LD. Genetic mapping of pathogenesis determinants in Toxoplasma gondii. AnnuRev Microbiol. 2016; 70:63-81. [DOI:10.1146/annurev-micro-091014-104353] [PMID]

[30] Harker K, Ueno N, Lodoen M. Toxoplasma gondii dissemination: a parasite's journey through the infected host. Parasite Immunol. 2015; 37(3):141-9. [DOI:10.1111/pim.12163] [PMID]

[31] Bogdan C, Röllinghoff M. How do protozoan parasites survive inside macrophages? Parasitology Today. 1999; 15(1):22-8. [DOI:10.1016/S0169-4758(98)01362-3]

[32] Molan A, Nosaka K, Hunter M, Wang W. The association between Toxoplasma gondii and type 2 diabetes mellitus: A systematic review and meta-analysis of human case-control studies. Bulletin of the National Research Centre. 2020; 44(7): [DOI:10.1186/s42269-019-0256-x]

[33] Majidiani H, Dalvand S, Daryani A, Galvan-Ramirez MdlL, Foroutan-Rad M. Is chronic toxoplasmosis a risk factor for diabetes mellitus? A systematic review and meta-analysis of case-control studies. Braz J Infect Dis. 2016; 20(6):605-9. [DOI:10.1016/j.bjid.2016.09.002] [PMID]

[34] Han Y, Nie L, Ye X, Zhou Z, Huang S, Zeng C, et al. The association between Toxoplasma gondii infection and hypertensive disorders in T2DM patients: A case-control study in the Han Chinese population. Parasitol Res. 2018; 117(3):689-95. [DOI:10.1007/s00436-017-5737-y] [PMID] 
[35] Henriquez S, Brett R, Alexander J, Pratt J, Roberts C. Neuropsychiatric disease and Toxoplasma gondii infection. Neuroimmunomodulation. 2009; 16(2):122-33. [DOI:10.1159/000180267] [PMID]

[36] Li YX, Xin H, Zhang XY, Wei CY, Duan YH, Wang HF, et al. Toxoplasma gondii infection in diabetes mellitus patients in China: Seroprevalence, risk factors, and case-control studies. Biomed Res. 2018; 2018. [DOI:10.1155/2018/4723739] [PMID] [PMCID]

[37] Siyadatpanah A, Tabatabaie F, Oormazdi H, Meamar $\mathrm{AH}$ Razmjou E, Hadighi R. Comparison of anti-Toxoplasma IgG and IgM antibodies determined by ELISA method in diabetic and non-diabetic individuals in west Mazandaran province, Iran, 2011-2012. Ann Biol Res. 2013; 4(6):281-5. https://www.researchgate.net/publication/309346790_st_mazandaran_province_iran

[38] Younis EZ, Elamami AH, Almnefy ME, Alsherif NA, Laraibe HA, Burnia AI. Anti-Toxoplasma gondii IgG, Ig M, and IgA among Type 2 diabetic Patients in Benghazi, Libya. A Comparison Study. Journal of Immunology and Microbiology. 2018; 2(1). https://www.imedpub.com/articles/antitoxoplasmagondii-igg-igm-and-iga-among-type2-diabetic-patients-inbenghazi-libya-a-comparison-study.php?aid=23789

[39] Su C, Zhang X, Dubey J. Genotyping of Toxoplasma gondii by multilocus PCR-RFLP markers: A high resolution and simple method for identification of parasites. Int J Parasitol. 2006; 36(7):841-8. [DOI:10.1016/j.ijpara.2006.03.003] [PMID]

[40] Mousavi M, Saravani R, Jafari Modrek M, Shahrakipour M, Sekandarpour S. Detection of Toxoplasma gondii in Diabetic Patients Using the Nested PCR Assay via RE and B1 Genes. Jundishapur J Microbiol. 2016; 9(2):e29493-e. [DOI:10.5812/ jjm.29493]

[41] Fazaeli A, Carter P, Darde M, Pennington T. Molecular typing of Toxoplasma gondii strains by GRA6 gene sequence analysis. Int J Parasitol. 2000; 30(5):637-42. [DOI:10.1016/S00207519(00)00036-9]

[42] Chaichan P, Mercier A, Galal L, Mahittikorn A, Ariey F, Morand S, et al. Geographical distribution of Toxoplasma gondii genotypes in Asia: A link with neighboring continents. Infect Genet Evol. 2017;53:227-38. [DOI:10.1016/j.meegid.2017.06.002] [PMID]

[43] Ajzenberg D, Yera H, Marty P, Paris L, Dalle F, Menotti J, et al. Genotype of 88 Toxoplasma gondii isolates associated with toxoplasmosis in immunocompromised patients and correlation with clinical findings. J Infect. 2009; 199(8):1155-67. [DOI:10.1086/597477] [PMID]

[44] Ramadan JW, Steiner SR, O'Neill CM, Nunemaker CS. The central role of calcium in the effects of cytokines on beta-cell function: Implications for type 1 and type 2 diabetes. Cell Calcium. 2011; 50(6):481-90. [DOI:10.1016/j.ceca.2011.08.005] [PMID] [PMCID]

[45] Carter C. Toxoplasmosis and polygenic disease susceptibility genes: Extensive Toxoplasma gondii host/pathogen interactome enrichment in nine psychiatric or neurological disorders. J Pathog. 2013; 2013:29. [DOI:10.1155/2013/965046] [PMID] [PMCID]

[46] Reeves GM, Postolache TT, Mazaheri S, Snitker S, Langenberg P, Giegling I, et al. A positive association between T. gondii seropositivity and obesity. Front Publ Health. 2013; 1:73. [DOI:10.3389/fpubh.2013.00073] [PMID] [PMCID]
[47] Oz HS. Toxoplasmosis, pancreatitis, obesity and drug discovery. Panc Dis Therap. 2014; 4(2):138. [PMCID] [PMID]

[48] Oz HS, Tobin T. Atovaquone ameliorate gastrointestinal toxoplasmosis complications in a pregnancy model. Med Sci Monit. 2012; 18(9):BR337. [DOI:10.12659/MSM.883342] [PMID] [PMCID] 
This Page Intentionally Left Blank 